\title{
Metastatic colo-rectal cancer: real life experience from an Indian tertiary care center
}

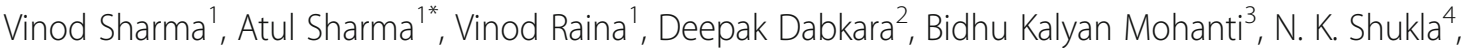 \\ Sushmita Pathy ${ }^{3}$, Sanjay Thulkar ${ }^{5}$, S. V. S. Deo ${ }^{4}$, Sunil Kumar ${ }^{4}$ and Ranjit Kumar Sahoo ${ }^{1}$
}

\begin{abstract}
Background: No data exist for the long-term outcome of metastatic colorectal cancer (mCRC) from the Southern part of Asia. The primary objective of the study is to evaluate the survival outcome of mCRC from an Indian tertiary care center. The study also aims to highlight the treatment pattern practiced and the unique clinico-pathologic characteristics.

Methods: This is a single-center retrospective observational study done at a large referral tertiary care center in North India. All patients with synchronous or metachronous mCRC who received at least one dose of chemotherapy for metastatic disease, registered between 2003 to 2017 were included. Primary outcome measures were overall survival and progression-free survival and prognostic factors of overall survival. Descriptive analysis was done for the clinicopathological characteristics and treatment patterns. Kaplan Meier method for overall survival and progression-free survival. Cox regression analysis was performed for the determination of the prognostic factors for overall survival.

Result: Out of 377 eligible patients, 256 patients (68\%) had de novo metastatic disease and the remaining 121 (32\%) progressed to metastatic disease after initial treatment. The cohort was young (median age, 46 years) with the most common primary site being the rectum. A higher proportion of signet (9\%) and mucinous histology (24\%). The three common sites of metastasis were the liver, peritoneum, and lung. In the first line, most patients received oxaliplatin-based chemotherapy (70\%). Only $12.5 \%$ of patients received biologicals in the first-line setting. The median follow-up and median overall survival of study cohort were 17 months and 18.5 months. The factors associated with poor outcome for overall survival on multivariate analysis were ECOG performance status of $>1$, high CEA, low albumin, and the number of lines of chemotherapy received $(<2)$.

Conclusion: The outcome of $\mathrm{mCRC}$ is inferior to the published literature. We found a relatively higher proportion of patients with the following characteristics; younger, rectum as primary tumor location, the signet, and mucinous histology, higher incidence of peritoneum involvement. The routine use of targeted therapies is limited. Government schemes (inclusion of targeted therapies in the Ayushman scheme), NGO assistance, and availability of generic low-cost targeted drugs may increase the availability.
\end{abstract}

Keywords: Metastatic, Colorectal cancer, Real life experience, India

\footnotetext{
* Correspondence: atul1@hotmail.com

'Department of Medical Oncology, Dr BRA IRCH, All India Institute of Medical Sciences (AllMS), New Delhi, India

Full list of author information is available at the end of the article
}

(c) The Author(s). 2021 Open Access This article is licensed under a Creative Commons Attribution 4.0 International License, which permits use, sharing, adaptation, distribution and reproduction in any medium or format, as long as you give appropriate credit to the original author(s) and the source, provide a link to the Creative Commons licence, and indicate if changes were made. The images or other third party material in this article are included in the article's Creative Commons licence, unless indicated otherwise in a credit line to the material. If material is not included in the article's Creative Commons licence and your intended use is not permitted by statutory regulation or exceeds the permitted use, you will need to obtain permission directly from the copyright holder. To view a copy of this licence, visit http://creativecommons.org/licenses/by/4.0/. The Creative Commons Public Domain Dedication waiver (http://creativecommons.org/publicdomain/zero/1.0/) applies to the data made available in this article, unless otherwise stated in a credit line to the data. 


\section{Introduction}

Colorectal cancer $(\mathrm{CRC})$ is important cause of cancer related morbidity and mortality. Worldwide, it stands second for cancer related mortality [1]. In South Central Asia (including India), the incidence and mortality of CRC is comparatively lower than the western world. However, half of the world cancer occur in Asia. Current literature suggest rise in the incidence of CRC in Asian countries (China, Singapore, Japan, Sri Lanka) [2, 3]. Fluoropyrimidine based combination therapy including either oxaliplatin (FOLFOX with various modifications, XELOX) or Irinotecan (FOLFIRI, XELIRI) plus targeted therapy is the current standard of care for metastatic colorectal cancer worldwide as incorporated by various guidelines [4]. The median overall survival has improved successively from 8 to 10 months with single agent drug to 18-24 months with chemotherapy doublets, with reaching up to 34 months with addition of biologics [5].

However, these advancements have not reached the routine day to day clinical management of metastatic CRC in many parts of the world. As per Globocan 2018, in India, CRC accounts for the sixth and seventh cause of cancer related disease burden and cancer related death respectively [1]. Despite a low prevalence, according to the National cancer registry programme, the expected number of CRC in India by 2020 will reach close to 100,000 [6]. This number is huge and it poses a great challenge to the treating physicians. In India, most patients are not insured and have to purchase costly drugs out of pocket. No established screening colorectal cancer programme exist. All CRC diagnosis are symptomatic at presentation.

The long term outcome and treatment pattern from Indian sub continents has not been published. Most of the studies has been focused on the clinico pathological characteristics including all stages and are limited by having small number of patients [7-9].

The primary goal of our study is to study the patient characteristics, prognostic factors, pattern of care using first and second line chemotherapy and associated prognostic outcome among patients with metastatic CRC treated at our institutions over the last 15 years. This is the first study from Indian sub-continent highlighting the treatment outcome of metastatic colorectal cancer from a tertiary care cancer centre.

\section{Materials and methods}

We conducted a retrospective analysis of patients with metastatic colorectal cancer, registered between January 2003 to December 2017. The study protocol was approved by the institutional ethical committee (AIIMS, All India Institute of Medical Sciences, New Delhi). Standard guidelines and regulations were followed for the study. The institute ethical committee (AIIMS, All
India Institute of Medical Sciences, New Delhi) also exempted the study from the informed consent. All files numbers were extracted from the patients record database - computer based system and in hospital day care record system to ensure screening for all patients with diagnosis of colorectal cancer. All files were screened and subsequently patients who received treatment for metastatic disease were retrieved. Only patients who received at least 1 cycle of chemotherapy with histopathological diagnosis of colorectal cancer were enrolled into the study. Patients treated with best supportive care and palliative RT only were not included.

Patient and treatment characteristics were filled in pre specified performa. The main objective of the study was to determine the overall survival and the prognostic factors affecting the outcome measures. Overall survival was calculated from the date of institution of first line chemotherapy for metastatic disease to the date of last follow up in surviving patients or date of death from any cause. The secondary objective was to determine the PFS and the prognostic factors determining it. Progression free survival (PFS) was calculated from the date of institution of first line chemotherapy for metastatic disease to the date of progressive disease or death from any cause whichever is first. Patients who were lost to follow up, were contacted telephonically for survival status. Data for surviving patients was censored on 31st December 2018. Response assessment was done first after at least 3-4 cycles (roughly 2 months) unless clinically indicated and then attempted to be every 4-6 months. Response assessment was done either using CECT (contrast enhanced computed tomography) or PET CT (positron emission tomography computed tomography) depending upon the availability of modality. Overall response rate (ORR) included partial response and complete response. Clinical benefit rate (CBR) included the sum of complete response, stable disease and partial response. All statistical computations were done using STATA software version 13. Descriptive analysis were done for baseline characteristics. Time to event analysis was done using Kaplan-Meier survival curve estimates. Cox regression analysis was performed for prognostic factor.

A number of chemotherapy regimen in standard dosing form were used over the last two decade. Standard doses of chemotherapy doublet were administered including FOLFIRI, CapeOx / XELOX (Capecitabine doses - $1 \mathrm{~g} / \mathrm{m} 2 / \mathrm{BD}$ for 2 weeks every 3 weekly), IFL etc. For initial few years, an institutional modified FOLFOX protocol constituting oxaliplatin $85 \mathrm{mg} / \mathrm{m} 2$ on day 1 and leucovorin (LV) $200 \mathrm{mg} / \mathrm{m} 2$, 5-FU (5- Fluorouracil) 400 $\mathrm{mg} / \mathrm{m} 2$ push, 5 -FU $600 \mathrm{mg} / \mathrm{m} 2$ over $8 \mathrm{~h}$, each on day 1 and 2 was instituted. Later the modified FOLFOX-6 regimen was used. Left side tumor included rectum, 
sigmoid colon, descending colon, splenic flexure of colon. Right sided tumor included hepatic flexure of colon, caecum and full length ascending colon.

\section{Result}

\section{Patient characteristics}

Between 2003 and 2017, a total of 2615 patients with the diagnosis of colorectal cancer were registered. Out of these, 377 were found eligible for the study enrollment. A large number of patients met the exclusion criteria ( $\mathrm{n}$ 2238). The various reasons for exclusion were earlystage disease (most common), wrong diagnosis, best supportive care, received outside treatment, as enlisted in the patient disposition flow diagram (Fig. 1). Two hundred and fifty six patients (68\%) presented with upfront metastatic disease and remaining 121 (32\%) progressed to metastatic disease after initial treatment.

The cohort was relatively young with median age of 46 years (range, 11 to 82 years). Six patients had age of less than 18 years. The ratio of male to female was $1.4: 1$ (Table 1). Young adults ( $\leq 40$ years) constituted $38 \%$ of study population. The median duration of symptoms in patients with up front metastatic disease was 6 months (range, 3-10 months). In relapsed cases, the median time to metastasis (time from treatment initiation for localized disease to relapse) was 15.5 months (range, 8-27 months). Most patients received systemic therapy with palliative intent and only few underwent curative resection. Three fourth of patient had ECOG PS of $0-1$. A positive family history of cancer was present in $12 \%$ of cases, with $6 \%$ being gastrointestinal and $2 \%$ were CRC.

\section{Tumor Characteristics (Symptom, Metastasis, Side, Pathology, and Mutation status)}

Most common symptom was abdominal pain or pain during defecation (65\%) followed by bleeding per rectum (57\%), altered bowel habits (52\%), weight loss (27\%) and obstruction (13\%). Most of the tumors were well to moderately differentiated (94\%) with one case of adenosquamous. A high proportion of patient had mucinous (24\%) morphology followed by signet (9.2\%). Proportion of left side and right side tumor was 75 and $20 \%$ (Table 2). The most common primary site was rectum (47\%) followed by sigmoid colon (17\%), caecum (8\%) and ascending colon (8.7\%). The mean number of the site of organ metastasis were $1.1(\mathrm{SD} \pm 0.42)$. The common sites of metastasis were liver (43\%), peritoneum (31\%), lung (18\%) followed by ovary (13\%) and bone (5\%). Nearly two third of the patients with liver metastasis had more than 3 lesions. Mean number of organs involved at diagnosis were 1.1 ( $\mathrm{SD} \pm 0.04$ ). The proportion of patients with one, two and three organ involvement was 76, 21 and $2.4 \%$ respectively. Mutational analysis was done in limited number of patients, the mutation

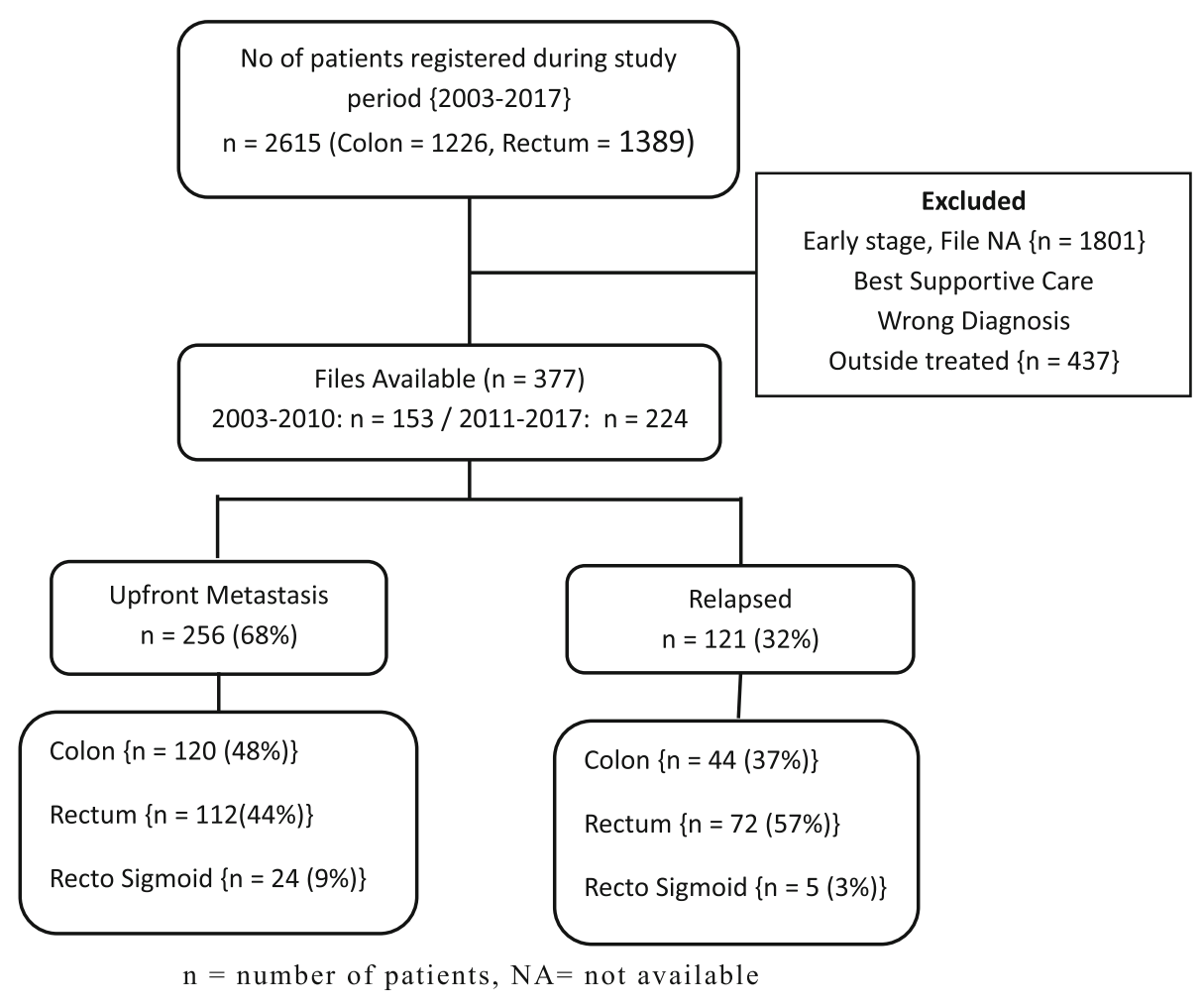

Fig. 1 Patient disposition Diagram. $n=$ number of patients, $N A=$ not available 
Table 1 Baseline characteristics, Pathology

\begin{tabular}{|c|c|}
\hline Variable & $\begin{array}{l}\text { Number (\%) of } \\
\text { patients }\end{array}$ \\
\hline Median Age (range) years & $46(11-82)$ \\
\hline Gender (Male / Female) & $219(58 \%) / 158(42 \%)$ \\
\hline Age $\leq 40 \mathrm{yrs}$. and $\geq 65 \mathrm{yrs}$ & $144(38 \%) / 33(8.8 \%)$ \\
\hline Median duration of symptoms, months & $6(3-10)$ \\
\hline \multicolumn{2}{|l|}{ ECOG performance status $(n=320)$} \\
\hline $0-1$ & $223(72 \%)$ \\
\hline $2-3$ & $89(28 \%)$ \\
\hline F/h of cancer / Gastrointestinal cancer $(n=320)$ & $38(12 \%) / 17(6 \%)$ \\
\hline $\begin{array}{l}\text { Upfront Metastasis / Relapsed post adjuvant } \\
\text { therapy }\end{array}$ & $256(68 \%) / 121(32 \%)$ \\
\hline \multicolumn{2}{|l|}{ Presenting symptoms (Up front metastasis) } \\
\hline Abdominal pain or pain during defecation & $168(65 \%)$ \\
\hline Bleeding Per rectum & $148(57 \%)$ \\
\hline Altered bowel habits & $136(52 \%)$ \\
\hline Weight loss & $70(27 \%)$ \\
\hline Obstruction & $34(13 \%)$ \\
\hline \multicolumn{2}{|l|}{ Laboratory parameters (median) } \\
\hline Hemoglobin $(n=321)$ & $10.7(9.3-12.3)$ \\
\hline Platelets $(n=320)$ & $\begin{array}{l}272,000(18600-336 \\
000)\end{array}$ \\
\hline Total leucocyte count $(n=320)$ & $7850(6400-9500)$ \\
\hline Albumin $(n=317)$ & $3.9(3.6-4.4)$ \\
\hline CEA (ng/ml) (median, $n=293$ ) & $22(5-117)$ \\
\hline High CEA level (> 5 ng/ml) & $228(78 \%)$ \\
\hline High Serum alkaline phosphatase $(n=307)$ & $11(3.6 \%)$ \\
\hline \multicolumn{2}{|l|}{ Grade $(n=342)$} \\
\hline Well / Moderately & $323(94 \%)$ \\
\hline Poorly differentiated & $19(6 \%)$ \\
\hline \multicolumn{2}{|l|}{ Morphology $(n=325)$} \\
\hline Adenocarcinoma NOS & $216(66 \%)$ \\
\hline Signet ring & $30(9.2 \%)$ \\
\hline Mucinous & $78(24 \%)$ \\
\hline Adenosquamous & $1(0.3 \%)$ \\
\hline
\end{tabular}

CEA carcinoembryonic antigen, NOS not otherwise specified

rate were \{KRAS $(22 / 70 ; 33 \%)$, NRAS $(1 / 33 ; 3 \%)$, BRAF (2/30; 7\%), MSI (8/32; 25\%).

\section{Treatment outcome}

All these patients (377 patients) received at-least one dose of chemotherapy for metastatic disease. Second line chemotherapy was administered in $33 \%(n=124)$ of study population. Oxaliplatin and irinotecan based chemotherapy was the main regimen used in 1st and 2nd line chemotherapy ( $71 \%$ vs $59 \%)$ respectively. The various chemotherapy regimen used in 1st line were CapeOx
Table 2 Sidedness, Metastasis pattern

\begin{tabular}{ll}
\hline Variable & Number (\%) of patients \\
\hline Right Side & $75(20 \%)$ \\
Caecum & $30(8 \%)$ \\
Ascending colon & $33(8.7 \%)$ \\
Hepatic flexure & $12(3.1 \%)$ \\
Left side & $285(76 \%)$ \\
Splenic flexure & $3(0.8 \%)$ \\
Descending colon & $13(3.5 \%)$ \\
Sigmoid colon & $64(17 \%)$ \\
Recto sigmoid & $29(7.7 \%)$ \\
Rectum & $176(47 \%)$ \\
Transverse Colon & $15(4 \%)$ \\
Metastasis & \\
Liver & $161(42.7 \%)$ \\
Peritoneum & $117(31 \%)$ \\
Lung & $68(18 \%)$ \\
Non regional lymph nodes & $57(15 \%)$ \\
Ovary & $49(13 \%)$ \\
Bone & $19(5 \%)$ \\
Skin & $3(0.8 \%)$ \\
Adrenal & $6(1.7 \%)$ \\
Number of metastatic site (Mean \pm SD) & $1.1 \pm 0.04$ \\
Number of organ involved & \\
\hline & $10(2.6 \%)$ \\
\hline & $101(63 \%)$ \\
\hline &
\end{tabular}

For 2 cases the primary site was not documented

followed by FOLFOX, FOLFIRI, CAPIRI etc (Table 3). Similarly in second line, the most common regimen was FOLFIRI (37\%) followed by CAPIRI (22\%), FOLFOX (15\%) and others. Median number of cycles received were 6 in both 1st and 2nd line therapy. Most patients received doublet regimen except few during early part of 20032005 when single agent chemotherapy was given. The type of first line chemotherapy doublet remained unchanged over the study duration. About $12.5 \%$ of patients received biologicals in first line. The proportion of patient who received biological agents in first, second and third were 12.5, 31.5 and $48 \%$ respectively (Table 4 ). The median number of chemotherapy lines given was 1 (range, 1 to 5 ). A documented response was available in 76 and $67 \%$ of patients respectively in first and second line. In first line setting, the progressive disease, overall response rate and stable disease were seen in 40,34 and $26 \%$ cases respectively. Similarly for second line, the overall response rate, stable disease, progressive disease were 22,32 , and $37 \%$ respectively (Table 5). 
Table 3 Chemotherapy regimen given in first and second line setting

\begin{tabular}{lll}
\hline Chemotherapy Line & Regimen & N (\%) \\
\hline First line & CapeOx & $166(44 \%)$ \\
& FOLFOX & $75(20 \%)$ \\
& FOLFIRI & $49(13 \%)$ \\
& CAPIRI & $34(9 \%)$ \\
& Capecitabine & $11(3 \%)$ \\
& FOLFOXIRI & $5(1.3 \%)$ \\
Second line & Others (FUFA, FLOX, IFL) & $37(10 \%)$ \\
& FOLFIRI & $47(37 \%)$ \\
& CAPIRI & $27(22 \%)$ \\
& FOLFOX & $19(15 \%)$ \\
& CapeOx & $14(11.3 \%)$ \\
& Others (IFL, Capecitabine, UFT, & $17(14 \%)$ \\
& FOLFOXIRI, Irinotecan) & \\
\hline
\end{tabular}

CapeOx, Capecitabine, oxaliplatin; FOLFOX, 5-FU, LV, oxaliplatin; FOLFIRI, 5-FU, LV, Irinotecan; CAPIRI, Capecitabine, Irinotecan; FOLFOXIRI, 5-FU, LV, oxaliplatin, Irinotecan; FUFA, 5-FU, LV; FLOX, 5-FU, oxaliplatin; IFL, 5-FU, Irinotecan, UFT -Uracil

The toxicity recording was not up to the mark. The major grade 3-4 toxicity seen with first line regimens was anemia (13.4\%), leucopenia (5\%), diarrhea (5.6\%), thrombocytopenia (5.6\%). The all grade peripheral neuropathy was $10 \%$, with grade $3-4$ being only seen in $1.6 \%$ of cases (data not shown).

With the median follow up was 17 months, the median progression free survival (PFS) and overall survival (OS) for the study cohort were 7.13 months and 18.5 months respectively (Fig. 2). The overall survival rate at 2 years, 3 years and 5 years of the entire cohort was 45, 37 and $23 \%$ respectively. The median overall survival for patients who received more than 1 line of chemotherapy was 23.4 months (95\% CI; $14-47$ months). For progression free survival, on univariate analysis significant factors were ECOG 0-1, Hemoglobin, CEA, hypoalbuminemia. On multivariate analysis only 2 factors came out to be significantly associated with poor PFS; high CEA and ECOG $>1$ (Table 6). On univariate analysis for overall survival four factors including ECOG Performance status (PS) $0-1$, the number of lines of chemotherapy, high CEA and hypoalbuminemia came out to be
Table 5 Response rate to first and second line

\begin{tabular}{lll}
\hline Response category & First line $(\%, \mathbf{n} \mathbf{3 1 0})$ & Second line $(\%, \mathbf{n ~ 8 3 )}$ \\
\hline ORR $^{\text {a }}$ & $34 \%$ & $22 \%$ \\
Stable Disease & $26 \%$ & $32 \%$ \\
CBR & $60 \%$ & $54 \%$ \\
Progressive Disease & $40 \%$ & $37 \%$ \\
\hline averall response rate & &
\end{tabular}

${ }^{\mathrm{b}}$ Clinical benefit rate

significant. On multivariate analysis using Cox regression, all these factors remained significant $(p<0.05)$ (Table 7). Use of biological therapies as covariate for overall survival and progression free survival was not significant.

\section{Discussion}

The study finds the presence of relatively younger cohort, high rate of rectal cancer, peritoneal metastasis and signet and mucinous histology. The poor performance status, low albumin, high CEA were predictors of poor survival outcome.

The median age at presentation of 46 years is in wide variance from the developed world where the median age is in 6th decade [10]. A number of studies done over the last 2 decades from India also suggest a similar median age [7-9]. A simple reason for the variance could be due to age pyramid of our country where most (80\%) of the population is under 50 years of age and low mean life years (67-69 years) [11]. The median duration of symptoms in our patients was 6 months (range, 3-10 months) similar to previous studies $[9,12]$. More than half of the patients presented with pain, bleeding per rectum, altered bowel habits. A significant proportion of patients carried family history of cancer (12\%) with 6\% being gastrointestinal ( $2 \%$ colon) [10].

Rectum was the most common site followed by the sigmoid colon, caecum, ascending colon and others. This is in contrast to developed countries, where rectum represents only $25-30 \%$ of all cases [12, 13]. Similar experience was observed in other studies across the country $[9,14]$. Adenocarcinoma-not otherwise specified is the most common histology (90\%) followed by mucinous and signet [15]. We found a significantly high percentage

Table 4 Chemotherapy lines and drug used

\begin{tabular}{lllllll}
\hline Chemotherapy line & Oxaliplatin & Irinotecan & VEGF MoAB & EGFR MoAB & CT alone & CT + MoAB \\
\hline $\begin{array}{l}1 \text { st (100\%) } \\
n=377\end{array}$ & $71 \%$ & $26 \%$ & $4.5 \%$ & $7.9 \%$ & $87.5 \%$ & $12.5 \%$ \\
$\begin{array}{l}\text { 2nd (33\%) } \\
n=124\end{array}$ & $26.4 \%$ & $59 \%$ & $19 \%$ & $12.6 \%$ & $68.5 \%$ & $31.5 \%$ \\
$\begin{array}{l}3 r d(8.4 \%) \\
n=32\end{array}$ & $48 \%$ & $29 \%$ & $30 \%$ & $17 \%$ & $52 \%$ & $48 \%$ \\
\hline
\end{tabular}

VEGF Vascular endothelial growth factor, MoAB monoclonal antibodies, CT chemotherapy, EGFR Epidermal growth factor receptor 

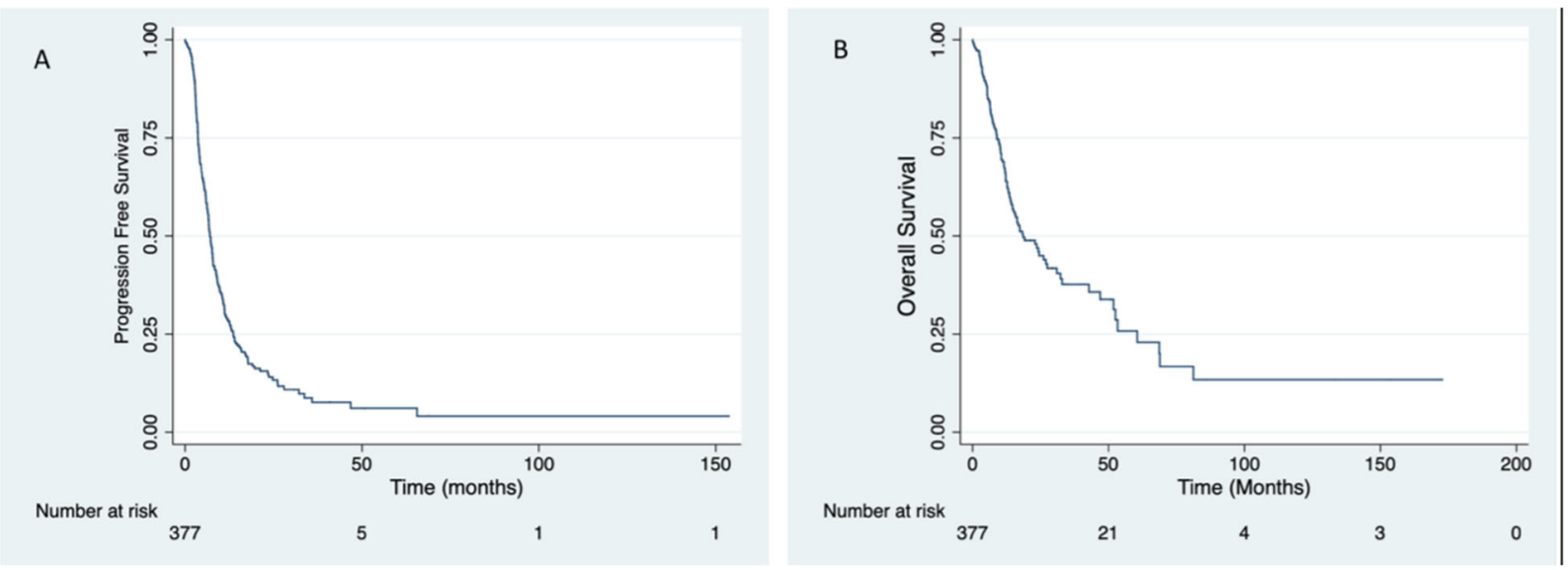

Fig. 2 Kaplan-Meier survival estimates: A Progression Free Survival (7.13 months); and B Overall Survival (18.5 months)

of patients with signet (9.2\%) and mucinous histology (24\%). A number of small studies done over the last 2 decade has repeatedly shown the similar observations [prevalence of signet ring morphology (13-19\%) and mucinous tumors $(16-31 \%)][9,16]$. We found higher rate of peritoneal metastasis (31\%) compared to $16-28 \%$ reported by Hugens et al. [15]. The high frequency of signet morphology in our cohort is probably the reason for the high frequency of peritoneal involvement. The frequency of KRAS (30\%) mutations were less than the internationally reported figures [17, 18]. A relatively lower rate of KRAS mutation positivity reported across India $(23-42 \%) \quad[19,20]$. These studies were heterogenous and large database will be needed to conclude definitively about the incidence of mutations in Indian population. KRAS mutation variation is also seen across various European countries (33.7-54.1\%) [21].

The objective response rate and progression free survival for first line chemotherapy regimen was $34 \%$ and 7 months similar to previous reported studies [22-24]. Overall survival and progression free survival in our study was 18.5 months and 7.13 months with a median follow up 17 months (Fig. 2). Tounigard et al. and Colucci et al., also reported a somewhat similar median overall survival of 21.5 months and 15 months with chemotherapy alone respectively. Only one third patients (33\%) received second line chemotherapy regimen. The exact cause for the limited use of second-line chemotherapy in the study cohort is not clear. However, the day-to-day practice suggests that it could be related to multiple factors. Most of the patients were not insured; out-of-pocket purchase is routine for chemotherapy administration. Cancer services are limited to a small number of government-aided hospitals providing affordable chemotherapy services. People often have to travel long distances to get cancer care, which affects compliance and unplanned interruption. The limited use of biologicals also marks similar findings. The other reason could be aggressive biology due to the high proportion of EOCRC (early onset colo-rectal cancer) patients. However, the overall response rate and progression-free survival were comparable to published literature with chemotherapy doublets.

We studied 18 variables as potential predictive factor for overall survival, on multivariate analysis poor ECOG at baseline $(\geq 2)$, high CEA, only one line of chemotherapy and hypoalbuminemia were associated with poor overall outcome. Poor ECOG at baseline has been proved to be a predictor of poor outcome in a number of studies [25, 26]. ECOG is one of the few important factors of Kohne prognostic and GERCOR score [26, 27]. High CEA has been variably reported as a poor prognostic factor in previous studies $[28,29]$. Stelzner et al. in a retrospective study of 186 patients with synchronous metastasis found poor PS and high CEA associated with poor outcome [25]. High baseline CEA has been found to be associated with poor outcome in a prospective randomized trial [22]. However in prognostic score model where a large number of poor outcome factors were studied, CEA lost its relative significance. The median overall survival of metastatic CRC has improved over the last 2 decade with the use of doublet chemotherapy, biologicals and increased number of drugs for later lines. In today's era, the treatment of CRC is considered as continuum of care [30]. The progression free survival for 1st and 2nd line therapy however remained more or less unchanged over the last one decade; but the sequential use of all effective drugs has improved the outcome reaching the median overall survival in current trials to 30-32 months. The best outcome can be achieved by providing the benefit of all active drugs in patient care. This was recently emphasized by Grothey et al. In a study of eleven phase III trials 
Table 6 Univariate and multivariate analysis of different prognostic factors for progression free survival

\begin{tabular}{|c|c|c|c|c|c|c|c|}
\hline \multirow[t]{2}{*}{ Variable } & \multirow[t]{2}{*}{$\mathrm{n}$} & \multicolumn{3}{|l|}{ Univariate Analysis } & \multicolumn{3}{|c|}{ Multivariate analysis } \\
\hline & & Hazard Ratio (HR) & $\mathbf{p}$ & $95 \% \mathrm{Cl}$ & $\mathrm{HR}$ & $p$ & $95 \% \mathrm{Cl}$ \\
\hline \multicolumn{8}{|l|}{ Sex } \\
\hline Female & 158 & 1.03 & 0.787 & $0.78-1.36$ & & & \\
\hline Male & 219 & & & & & & \\
\hline \multicolumn{8}{|l|}{ Elderly } \\
\hline$>65$ yrs & 33 & 0.75 & 0.243 & $0.46-1.2$ & & & \\
\hline$\leq 65 \mathrm{yrs}$ & 344 & & & & & & \\
\hline \multicolumn{8}{|l|}{ Young } \\
\hline$\leq 40 \mathrm{yrs}$ & 144 & 1.3 & 0.051 & $0.99-1.73$ & & & \\
\hline$>40$ yrs & 233 & & & & & & \\
\hline \multicolumn{8}{|l|}{ ECOG } \\
\hline$\geq 2$ & 89 & 1.58 & 0.005 & $1.15-2.17$ & 1.5 & 0.032 & $1.03-1.6$ \\
\hline $0-1$ & 223 & & & & & & \\
\hline \multicolumn{8}{|l|}{ Upfront } \\
\hline Metastasis & 256 & 1.22 & 0.182 & $0.91-1.63$ & & & \\
\hline Relapsed & 121 & & & & & & \\
\hline \multicolumn{8}{|l|}{$\mathrm{Hb}(\mathrm{g} / \mathrm{dl})$} \\
\hline$<10.8$ & 165 & 1.48 & 0.006 & $1.12-1.96$ & 1.14 & 0.44 & $0.8-1.6$ \\
\hline$\geq 10.8$ & 156 & & & & & & \\
\hline \multicolumn{8}{|l|}{ CEA } \\
\hline High & 228 & 1.66 & 0.008 & $1.14-2.42$ & 1.80 & 0.005 & $1.2-2.7$ \\
\hline Normal & 65 & & & & & & \\
\hline \multicolumn{8}{|l|}{ Albumin(g/dl) } \\
\hline$<3.5$ & 54 & 1.49 & 0.043 & $1.01-2.20$ & 1.26 & 0.309 & $0.8-1.96$ \\
\hline$\geq 3.5$ & 263 & & & & & & \\
\hline \multicolumn{8}{|l|}{ Sidedness } \\
\hline Left & 285 & 1.06 & 0.71 & $0.76-1.48$ & & & \\
\hline Right & 75 & & & & & & \\
\hline \multicolumn{8}{|l|}{ Grade } \\
\hline Poorly & 19 & 1.60 & 0.12 & $0.87-2.9$ & & & \\
\hline Moderately / Well & 304 & & & & & & \\
\hline \multicolumn{8}{|l|}{ Morphology } \\
\hline Signet / Mucinous & 108 & 1.16 & 0.33 & $0.86-1.56$ & & & \\
\hline Adenoca NOS & 216 & & & & & & \\
\hline \multicolumn{8}{|l|}{ SAP } \\
\hline High & 11 & 1.67 & 0.216 & $0.73-3.82$ & & & \\
\hline Normal & 296 & & & & & & \\
\hline \multicolumn{8}{|l|}{ No of organs involved } \\
\hline$\geq 2$ & 90 & 1.3 & 0.09 & $0.95-1.80$ & & & \\
\hline 1 & 287 & & & & & & \\
\hline \multicolumn{8}{|l|}{ Liver metastasis } \\
\hline Yes & 161 & 1.08 & 0.573 & $0.82-1.42$ & & & \\
\hline No & 216 & & & & & & \\
\hline
\end{tabular}


Table 6 Univariate and multivariate analysis of different prognostic factors for progression free survival (Continued)

\begin{tabular}{|c|c|c|c|c|c|c|c|}
\hline \multirow[t]{2}{*}{ Variable } & \multirow[t]{2}{*}{$\mathrm{n}$} & \multicolumn{3}{|l|}{ Univariate Analysis } & \multicolumn{3}{|c|}{ Multivariate analysis } \\
\hline & & Hazard Ratio (HR) & $p$ & $95 \% \mathrm{Cl}$ & HR & $p$ & $95 \% \mathrm{Cl}$ \\
\hline \multicolumn{8}{|c|}{ Peritoneum metastasis } \\
\hline Yes & 117 & 1.13 & 0.40 & $0.84-1.52$ & & & \\
\hline No & 300 & & & & & & \\
\hline \multicolumn{8}{|c|}{ No of liver Metastasis } \\
\hline$>3$ & 89 & 1.17 & 0.475 & $0.75-1.85$ & & & \\
\hline$\leq 3$ & 51 & & & & & & \\
\hline \multicolumn{8}{|l|}{$C T$} \\
\hline Irinotecan & 90 & 1.25 & 0.162 & $0.91-1.72$ & & & \\
\hline Oxaliplatin & 247 & & & & & & \\
\hline
\end{tabular}

CT Chemotherapy, $\mathrm{Hb}$ hemoglobin, ECOG Eastern Cooperative Oncology group, CEA carcinoembryonic antigen, High CEA $>5 \mathrm{ng} / \mathrm{ml}$, SAP Serum Alkaline Phosphate, Cl Confidence interval, HR Hazard Ratio

in advanced colorectal cancer, multivariate analysis showed association of overall survival with more number of drugs exposed [31]. In our study those who received more than one line of chemotherapy had better outcome with median overall survival of 23.4 months (95\% CI; $14-47$ months).

Sidedness has been recently identified to be significant prognostic factor for survival outcome. Right and left defined variably has been shown to be associated with survival difference. In CALGB 80405 study, the median OS was significantly better in left side cancers. The overall survival of the left and right side tumor with bevacizumab (32.6 months and 29.2 months) and cetuximab (39.3 months and 13.6 months) was remarkably different respectively [32]. The magnitude of difference appeared to be more pronounced with the use of anti-EGFR inhibitors. In FIRE-3 study, the median OS of the right side tumor was 23 months and 18.3 months with bevacizumab and cetuximab. For the left side tumor, the median OS with bevacizumab and cetuximab was 28 months and 38.3 months respectively [33]. The difference between the median OS of the left and right side in our cohort was clinically meaningful but did not reach statistical significance (23 and 11 months, CI: $0.48-1.09, p=0.72$ ) probably due to small numbers.

For PFS, on multivariate analysis, high CEA, ECOG $>1$ came out to be the predictor for worse outcome. Good performance status has been found associated with better PFS with both single agent and doublet chemotherapy regimens across several studies [22, 34-36]. In NORDIC-VII study, on sub group analysis the PFS benefit with addition of cetuximab was seen in patients with good performance status, KRAS mutant and single metastatic site [37]. On the contrary, the poor prognostic significance of high CEA level at baseline is less conclusive but is documented across in few studies [34, 38].
The study cohort was rich for early-onset colorectal cancer (EOCRC, up to 40 years - 38\%). It showed prognostic significance for progression-free survival on univariate analysis only. Existing literature suggests variable prognostic importance [39]. The last four decade has noticed a significant rise in the incidence and mortality of EOCRC globally [3, 40]. EOCRC cancers are comparatively rich in MSI-high status (11-30\%), left-sided (73\%, especially rectum), risk of synchronous and metachronous tumors, germline mutations(16-35\%), signet ring morphology (3-6\%), and lynch syndrome $(8-18 \%)$ [39, $41,42]$. Signet ring morphology and MSI-high status are associated with poor outcomes [39, 42]. In our study cohort, three fourth of signet ring CRC occurred in the EOCRC sub-group. In half of the cases, the primary site was the rectum.

The outcome in our study is inferior than the worldwide literature. The role of biologicals and targeted therapies in improving outcome of metastatic CRC has been well documented. The most likely reason for the inferior outcome compared to developed nations appears to be related to the lack of exposure to subsequent lines of therapy and use of biologicals.

Major limitations of our study is retrospective study design which carries inherent selection bias. Being tertiary care center chances of referral bias was high. The information about the proportion of patients who underwent metastectomy and curative resection was not recorded as very small number (one digit) of patients underwent the procedure. None underwent percutaneous ablation and other local therapies.

\section{Conclusion}

Compared to developed countries, the survival outcome were numerically lower. Well defined prognostic factors (ECOG PS, Albumin, CEA, lines of chemotherapy) were found significant for overall survival. In real word, very 
Table 7 Univariate and multivariate analysis of different prognostic factors for overall survival

\begin{tabular}{|c|c|c|c|c|c|c|c|}
\hline \multirow[t]{2}{*}{ Variable } & \multirow[t]{2}{*}{$\mathrm{n}$} & \multicolumn{3}{|c|}{ Univariate Analysis } & \multicolumn{3}{|c|}{ Multivariate analysis } \\
\hline & & $\mathrm{HR}$ & $p$ & $95 \% \mathrm{Cl}$ & HR & $p$ & $95 \% \mathrm{Cl}$ \\
\hline \multicolumn{8}{|l|}{ Sex } \\
\hline Female & 158 & 1.06 & 0.716 & $0.74-1.52$ & & & \\
\hline Male & 219 & & & & & & \\
\hline \multicolumn{8}{|l|}{ Elderly } \\
\hline$>65 \mathrm{yrs}$ & 33 & 0.7 & 0.298 & $0.38-1.33$ & & & \\
\hline$\leq 65 \mathrm{yrs}$ & 344 & & & & & & \\
\hline \multicolumn{8}{|l|}{ Young } \\
\hline$\leq 40 \mathrm{yrs}$ & 144 & 1.31 & 0.91 & $0.83-1.89$ & & & \\
\hline$>40 \mathrm{yrs}$ & 233 & & & & & & \\
\hline \multicolumn{8}{|l|}{ ECOG } \\
\hline$\geq 2$ & 89 & 1.79 & 0.005 & $1.18-2.70$ & 2.0 & 0.003 & $1.3-3.3$ \\
\hline $0-1$ & 223 & & & & & & \\
\hline \multicolumn{8}{|l|}{ Upfront } \\
\hline Metastasis & 259 & 1.23 & 0.297 & $0.83-1.81$ & & & \\
\hline Relapsed & 118 & & & & & & \\
\hline \multicolumn{8}{|l|}{$\mathrm{Hb}(\mathrm{g} / \mathrm{dl})$} \\
\hline$<10.8$ & 165 & 1.45 & 0.076 & $0.96-2.04$ & & & \\
\hline$\geq 10.8$ & 156 & & & & & & \\
\hline \multicolumn{8}{|l|}{ CEA } \\
\hline High & 228 & 1.94 & 0.019 & $1.16-3.38$ & 2.47 & 0.004 & $1.33-4.6$ \\
\hline Normal & 65 & & & & & & \\
\hline \multicolumn{8}{|l|}{ Albumin $(\mathrm{g} / \mathrm{dl})$} \\
\hline$<3.5$ & 54 & 2.48 & 0.001 & $1.56-3.95$ & 1.71 & 0.045 & $1.0-2.9$ \\
\hline$\geq 3.5$ & 263 & & & & & & \\
\hline \multicolumn{8}{|l|}{ Sidedness } \\
\hline Left & 285 & 0.72 & 0.124 & $0.48-1.09$ & & & \\
\hline Right & 75 & & & & & & \\
\hline \multicolumn{8}{|l|}{ Grade } \\
\hline Poorly & 19 & 2.11 & 0.077 & $0.92-4.85$ & & & \\
\hline Moderately / Well & 304 & & & & & & \\
\hline \multicolumn{8}{|l|}{ Morphology } \\
\hline Signet / Mucinous & 108 & 1.43 & 0.072 & $0.96-2.11$ & & & \\
\hline Adenoca NOS & 216 & & & & & & \\
\hline \multicolumn{8}{|l|}{ SAP } \\
\hline High & 11 & 1.57 & 0.442 & $0.49-4.98$ & & & \\
\hline Normal & 296 & & & & & & \\
\hline \multicolumn{8}{|l|}{ No of organs involved } \\
\hline$\geq 2$ & 89 & 1.43 & 0.085 & $0.95-2.15$ & & & \\
\hline 1 & 287 & & & & & & \\
\hline \multicolumn{8}{|l|}{ Liver metastasis } \\
\hline Yes & 161 & 0.98 & 0.90 & $0.68-1.39$ & & & \\
\hline No & 216 & & & & & & \\
\hline
\end{tabular}


Table 7 Univariate and multivariate analysis of different prognostic factors for overall survival (Continued)

\begin{tabular}{|c|c|c|c|c|c|c|c|}
\hline \multirow[t]{2}{*}{ Variable } & \multirow[t]{2}{*}{$\mathrm{n}$} & \multicolumn{3}{|c|}{ Univariate Analysis } & \multicolumn{3}{|c|}{ Multivariate analysis } \\
\hline & & HR & $p$ & $95 \% \mathrm{Cl}$ & $\overline{H R}$ & $p$ & $95 \% \mathrm{Cl}$ \\
\hline \multicolumn{8}{|c|}{ Peritoneum metastasis } \\
\hline Yes & 118 & 1.3 & 0.155 & $0.90-1.92$ & & & \\
\hline No & 259 & & & & & & \\
\hline \multicolumn{8}{|c|}{ Number of liver metastasis } \\
\hline$>3$ & 89 & 1.15 & 0.712 & $0.62-1.99$ & & & \\
\hline$\leq 3$ & 51 & & & & & & \\
\hline \multicolumn{8}{|l|}{ 1st Line } \\
\hline Irinotecan & 90 & 1.1 & 0.54 & $0.76-1.6$ & & & \\
\hline Oxaliplatin & 247 & & & & & & \\
\hline \multicolumn{8}{|c|}{ Number of lines of $C T$} \\
\hline$>1$ & 124 & 0.48 & 0.001 & $0.32-0.7$ & 0.47 & 0.001 & $0.3-0.74$ \\
\hline 1 & 253 & & & & & & \\
\hline
\end{tabular}

CT Chemotherapy, $\mathrm{Hb}$ hemoglobin, ECOG Eastern Cooperative Oncology group, CEA carcinoembryonic antigen, High CEA > $5 \mathrm{ng} / \mathrm{ml}$, SAP Serum Alkaline Phosphate, $\mathrm{Cl}$ Confidence interval, HR Hazard Ratio

few patients got the opportunity to benefit from biologicals, successive lines of chemotherapy and metastasectomy. The study suggest to focus on measures to increase the availability of biologicals through various measures including involvement of patient assistance programme and government assistance schemes. Studies aimed to explore the predictive factors of successful administration of successive lines of therapy are needed. Translational research should be expedited for the distinct epidemiological and clinico-pathological characteristics of colorectal cancer.

\section{Abbreviations}

CRC: Colorectal Cancer; CEA: Carcinoembryonic Antigen; ECOG : Eastern Cooperative Oncology Group ; PFS: Progression Free Survival; OS: Overall Survival; PS: Performance Status; CECT: Contrast Enhanced Computed Tomography; PET CT: Positron Emission Tomography Computed Tomography; ORR: Overall Response Rate; CBR: Clinical Benefit Rate

\section{Acknowledgements}

We are thankful to all the patients and their family who trusted and received treatment at our center and are part of the study.

\section{Authors' contributions}

AS and VS were involved in all aspects of the study. DD helped in data acquisition. VR, BKM, NKS, SVS, ST, SP, SK, DD and RKS contributed to data interpretation, critical revision and final approval of the manuscript. The authors read and approved the final manuscript.

\section{Funding}

None.

\section{Availability of data and materials}

The data sharing was not part of ethical approval and thus currently not available. However if required, data can be shared after approval by ethical committee. A email request can be sent to the corresponding author.

\section{Declarations}

Ethics approval and consent to participate

Ethical approval was taken from institute ethical committee (AIIMS, All India Institute of Medical Sciences, New Delhi). Informed consent was exempted by the ethical committee (AlIMS, All India Institute of Medical Sciences, New Delhi).

Consent for publication

Not applicable.

\section{Competing interests}

None.

\section{Author details}

'Department of Medical Oncology, Dr BRA IRCH, All India Institute of Medical Sciences (AlIMS), New Delhi, India. ${ }^{2}$ Department of Medical Oncology, Tata Memorial Center, Kolkata, India. ${ }^{3}$ Department of Radiotherapy, Dr BRA IRCH, All India Institute of Medical Sciences (AlIMS), New Delhi, India. ${ }^{4}$ Department of Surgical Oncology, Dr BRA IRCH, All India Institute of Medical Sciences (AlIMS), New Delhi, India. ${ }^{5}$ Department of Radiodiagnosis, Dr BRA IRCH, All India Institute of Medical Sciences (AlIMS), New Delhi, India.

Received: 1 March 2021 Accepted: 6 May 2021

Published online: 28 May 2021

\section{References}

1. IACR - GLOBOCAN [Internet]. [cited 2020 May 15]. Available from: http:// www.iacr.com.fr/index.php?option=com_content\&view=article\&id=101 \&ltemid $=578$

2. Sung JJ, Lau JY, Goh K, Leung W. Increasing incidence of colorectal cancer in Asia: implications for screening. Lancet Oncol. 2005;6(11):871-6. https:// doi.org/10.1016/S1470-2045(05)70422-8.

3. Mathew A, Baby B, Wang K, Sirohi B, Lei F, Chen Q, et al. Colorectal cancer incidence in younger adults in India. Gut. 2020;69(10):1899-900. https://doi. org/10.1136/gutjnl-2019-320271.

4. Yoshino T, Arnold D, Taniguchi $H$, Pentheroudakis G, Yamazaki K, Xu R-H, et al. Pan-Asian adapted ESMO consensus guidelines for the management of patients with metastatic colorectal cancer: a JSMO-ESMO initiative endorsed by CSCO, KACO, MOS, SSO and TOS. Ann Oncol Off J Eur Soc Med Oncol. 2018;29(1):44-70.

5. Mahipal A, Grothey A. Role of biologics in first-line treatment of colorectal Cancer. J Oncol Pract. 2016;12(12):1219-28. https://doi.org/10.1200/JOP.2016. 018382. 
6. NCRP Anual Reports... [Internet]. [cited 2020 May 15]. Available from: http:// ncdirindia.org/NCRP/Annual_Reports.aspx

7. Deo SV, Shukla NK, Srinivas G, Mohanti BK, Raina V, Sharma A, et al. Colorectal cancers--experience at a regional cancer Centre in India. Trop Gastroenterol Off J Dig Dis Found. 2001;22(2):83-6.

8. Deo S, Kumar S, Shukla NK, Kar M, Mohanti BK, Sharma A, et al. Patient profile and treatment outcome of rectal cancer patients treated with multimodality therapy at a regional cancer center. Indian J Cancer. 2004; 41(3):120-4.

9. Patil PS, Saklani A, Gambhire P, Mehta S, Engineer R, De'Souza A, et al. Colorectal Cancer in India: an audit from a tertiary Center in a low Prevalence Area. Indian J Surg Oncol. 2017;8(4):484-90. https://doi.org/10.1 007/s13193-017-0655-0.

10. Thompson MR, O'Leary DP, Flashman K, Asiimwe A, Ellis BG, Senapati A. Clinical assessment to determine the risk of bowel cancer using symptoms, age, mass and Iron deficiency anaemia (SAMI). Br J Surg. 2017;104(10):1393404. https://doi.org/10.1002/bjs.10573.

11. Census of India Website: Office of the Registrar General \& Census Commissioner, India [Internet]. [cited 2020 May 15]. Available from: https:/ censusindia.gov.in/

12. Majumdar SR, Fletcher RH, Evans AT. How does colorectal cancer present? Symptoms, duration, and clues to location. Am J Gastroenterol. 1999;94(10): 3039-45. https://doi.org/10.1111/j.1572-0241.1999.01454.x.

13. Cancer Research UK [Internet]. [cited 2020 May 15]. Available from: https:// www.cancerresearchuk.org/

14. Peedikayil MC, Nair P, Seena SM, Radhakrishnan L, Sadasivan S, Naryanan VA, et al. Colorectal cancer distribution in 220 Indian patients undergoing colonoscopy. Indian J Gastroenterol Off J Indian Soc Gastroenterol. 2009; 28(6):212-5. https://doi.org/10.1007/s12664-009-0087-z.

15. Hugen $\mathrm{N}$, van de Velde $\mathrm{CJH}$, de Wilt JHW, Nagtegaal ID. Metastatic pattern in colorectal cancer is strongly influenced by histological subtype. Ann Oncol Off J Eur Soc Med Oncol. 2014;25(3):651-7. https://doi.org/10.1093/a nnonc/mdt591.

16. Mukherji A, Rathi AK, Sharma K, Kumar V, Singh K, Bahadur AK. A study on presentation and behavior of Colo-rectal carcinoma in young Indian patients. Trop Gastroenterol Off J Dig Dis Found. 2011;32(2):122-7.

17. Douillard J-Y, Oliner KS, Siena S, Tabernero J, Burkes R, Barugel M, et al. Panitumumab-FOLFOX4 treatment and RAS mutations in colorectal Cancer. N Engl J Med. 2013;369(11):1023-34. https://doi.org/10.1056/NEJMoa1305275.

18. Tejpar S, Schlichting M, Zubel A, Celik I, Rougier P, Ciardiello F. Cetuximab plus irinotecan, fluorouracil, and Leucovorin as first-line treatment for metastatic colorectal Cancer: updated analysis of overall survival according to tumor KRAS and BRAF mutation status. J Clin Oncol. 2011;29(15):2011-9.

19. Jauhri M, Bhatnagar A, Gupta S, BP M, Minhas S, Shokeen Y, et al. Prevalence and coexistence of KRAS, BRAF, PIK3CA, NRAS, TP53, and APC mutations in Indian colorectal cancer patients: next-generation sequencingbased cohort study. Tumor Biol. 2017;39(2):1010428317692265. https://doi. org/10.1177/1010428317692265.

20. Bisht S, Ahmad F, Sawaimoon S, Bhatia S, Das BR. Molecular spectrum of KRAS, BRAF, and PIK3CA gene mutation: determination of frequency, distribution pattern in Indian colorectal carcinoma. Med Oncol. 2014;31(9): 124. https://doi.org/10.1007/s12032-014-0124-3.

21. Kafatos $G$, Niepel D, Lowe K, Jenkins-Anderson S, Westhead H, Garawin T, et al. RAS mutation prevalence among patients with metastatic colorectal cancer: a meta-analysis of real-world data. Biomark Med. 2017;11(9):751-60. https://doi.org/10.2217/bmm-2016-0358.

22. Tournigand $\mathrm{C}$, André T, Achille E, Lledo G, Flesh M, Mery-Mignard D, et al. FOLFIRI followed by FOLFOX6 or the reverse sequence in advanced colorectal Cancer: a randomized GERCOR study. J Clin Oncol. 2004;22(2): 229-37. https://doi.org/10.1200/JCO.2004.05.113.

23. Colucci G, Gebbia V, Paoletti G, Giuliani F, Caruso M, Gebbia N, et al. Phase III randomized trial of FOLFIRI versus FOLFOX4 in the treatment of advanced colorectal Cancer: a multicenter study of the Gruppo Oncologico Dell'Italia Meridionale. J Clin Oncol. 2005;23(22):4866-75. https://doi.org/1 0.1200/JCO.2005.07.113.

24. Giacchetti S, Perpoint B, Zidani R, Le Bail N, Faggiuolo R, Focan C, et al. Phase III multicenter randomized trial of oxaliplatin added to chronomodulated fluorouracil-leucovorin as first-line treatment of metastatic colorectal cancer. J Clin Oncol Off J Am Soc Clin Oncol. 2000; 18(1):136-47. https://doi.org/10.1200/JCO.2000.18.1.136.
25. Stelzner S, Hellmich G, Koch R, Ludwig K. Factors predicting survival in stage IV colorectal carcinoma patients after palliative treatment: a multivariate analysis. J Surg Oncol. 2005;89(4):211-7. https://doi.org/10.1 002/jso.20196.

26. Chibaudel B, Bonnetain F, Tournigand C, Bengrine-Lefevre L, Teixeira L, Artru $P$, et al. Simplified prognostic model in patients with oxaliplatin-based or irinotecan-based first-line chemotherapy for metastatic colorectal cancer: a GERCOR study. Oncologist. 2011;16(9):1228-38. https://doi.org/10.1634/ theoncologist.2011-0039.

27. Köhne $\mathrm{CH}$, Cunningham D, Di Costanzo F, Glimelius B, Blijham G, Aranda E, et al. Clinical determinants of survival in patients with 5 -fluorouracil-based treatment for metastatic colorectal cancer: results of a multivariate analysis of 3825 patients. Ann Oncol Off J Eur Soc Med Oncol. 2002;13(2):308-17. https://doi.org/10.1093/annonc/mdf034.

28. Yuste AL, Aparicio J, Segura A, López-Tendero P, Gironés R, Pérez-Fidalgo $J A$, et al. Analysis of clinical prognostic factors for survival and time to progression in patients with metastatic colorectal Cancer treated with 5fluorouracil—based chemotherapy. Clin Colorectal Cancer. 2003;2(4):231-4. https://doi.org/10.3816/CCC.2003.n.004.

29. Prager GW, Braemswig KH, Martel A, Unseld M, Heinze G, Brodowicz T, et al. Baseline carcinoembryonic antigen (CEA) serum levels predict bevacizumabbased treatment response in metastatic colorectal cancer. Cancer Sci. 2014; 105(8):996-1001. https://doi.org/10.1111/cas.12451.

30. Goldberg RM, Rothenberg ML, Van Cutsem E, Benson AB, Blanke CD, Diasio $\mathrm{RB}$, et al. The continuum of care: a paradigm for the Management of Metastatic Colorectal Cancer. Oncologist. 2007;12(1):38-50. https://doi.org/1 0.1634/theoncologist.12-1-38

31. Grothey A, Sargent D. Overall survival of patients with advanced colorectal cancer correlates with availability of fluorouracil, irinotecan, and oxaliplatin regardless of whether doublet or single-agent therapy is used first line. J Clin Oncol Off J Am Soc Clin Oncol. 2005;23(36):9441-2. https://doi.org/1 $0.1200 / J C O .2005 .04 .4792$

32. Venook AP, Niedzwiecki D, Lenz H-J, et al. Effect of first-line chemotherapy combined with cetuximab or bevacizumab on overall survival in patients with KRAS wild-type advanced or metastatic colorectal cancer: a randomized clinical trial. JAMA. 2017;317(23):2392. https://doi.org/10.1001/ja ma.2017.7105.

33. Tejpar S, Stintzing S, Ciardiello F, Tabernero J, Van Cutsem E, Beier F, et al. Prognostic and predictive relevance of primary tumor location in patients with RAS wild-type metastatic colorectal Cancer: retrospective analyses of the CRYSTAL and FIRE-3 trials. JAMA Oncol. 2017;3(2):194-201. https://doi. org/10.1001/jamaoncol.2016.3797.

34. Fountzilas G, Gossios K, Zisiadis A, Svarna E, Skarlos D, Pavlidis N. Prognostic variables in patients with advanced colorectal cancer treated with fluorouracil and leucovorin-based chemotherapy. Med Pediatr Oncol. 1996;26(5):305-17. https:/doi. org/10.1002/(SICl) 1096-911X(199605)26:5<305:AID-MPO2>3.0.CO;2-M.

35. Mitry E, Douillard J-Y, Van Cutsem E, Cunningham D, Magherini E, MeryMignard D, et al. Predictive factors of survival in patients with advanced colorectal cancer: an individual data analysis of 602 patients included in irinotecan phase III trials. Ann Oncol. 2004;15(7):1013-7. https://doi.org/10.1 093/annonc/mdh267.

36. de Gramont A, Figer A, Seymour M, Homerin M, Hmissi A, Cassidy J, et al. Leucovorin and fluorouracil with or without oxaliplatin as first-line treatment in advanced colorectal cancer. J Clin Oncol Off J Am Soc Clin Oncol. 2000;18(16):2938-47. https://doi.org/10.1200/JCO.2000.18.16.2938.

37. Tveit KM, Guren T, Glimelius B, Pfeiffer P, Sorbye H, Pyrhonen S, et al. Phase III trial of Cetuximab with continuous or intermittent fluorouracil, Leucovorin, and Oxaliplatin (Nordic FLOX) versus FLOX alone in first-line treatment of metastatic colorectal Cancer: the NORDIC-VII study. J Clin Oncol. 2012;30(15):1755-62. https://doi.org/10.1200/JCO.2011.38.0915.

38. De Divitiis C. Prognostic and predictive response factors in colorectal cancer patients: between hope and reality. World J Gastroenterol. 2014;20(41): 15049-59. https://doi.org/10.3748/wjg.v20.141.15049.

39. Akimoto N, Ugai T, Zhong R, Hamada T, Fujiyoshi K, Giannakis M, et al. Rising incidence of early-onset colorectal cancer - a call to action. Nat Rev Clin Oncol. 2021;18(4):230-43. https://doi.org/10.1038/s41571-020-00445-1.

40. Siegel RL, Torre LA, Soerjomataram I, Hayes RB, Bray F, Weber TK, et al. Global patterns and trends in colorectal cancer incidence in young adults. Gut. 2019;68(12):2179-85. https://doi.org/10.1136/qutjnl-2019-319511. 
41. Hofseth L, Hebert JR, Chanda A, Chen H, Love BL, Pena MM, et al. Early-onset colorectal cancer: initial clues and current views. Nat Rev Gastroenterol Hepatol. 2020;17(6):352-64. https:/doi.org/10.1038/s41575-019-0253-4.

42. Pokharkar AB, Bhandare M, Patil P, Mehta S, Engineer R, Saklani AP. Young vs old colorectal Cancer in Indian subcontinent: a tertiary care center experience. Indian J Surg Oncol. 2017;8(4):491-8. https://doi.org/10.1007/ s13193-017-0670-1.

\section{Publisher's Note}

Springer Nature remains neutral with regard to jurisdictional claims in published maps and institutional affiliations.

Ready to submit your research? Choose BMC and benefit from:

- fast, convenient online submission

- thorough peer review by experienced researchers in your field

- rapid publication on acceptance

- support for research data, including large and complex data types

- gold Open Access which fosters wider collaboration and increased citations

- maximum visibility for your research: over $100 \mathrm{M}$ website views per year

At $\mathrm{BMC}$, research is always in progress.

Learn more biomedcentral.com/submissions 